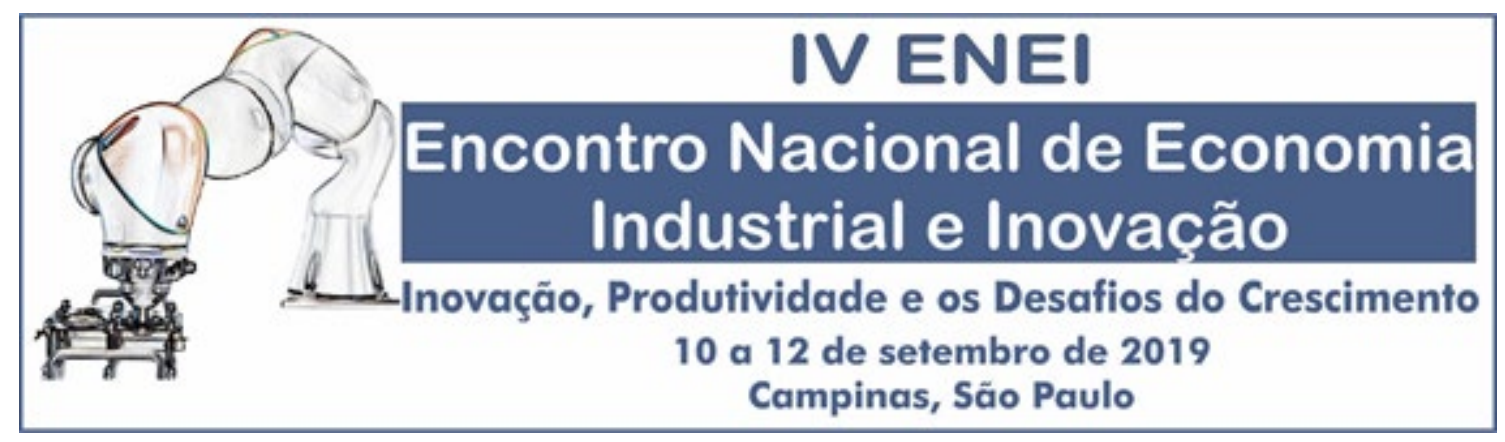

\author{
Igor Castellano da Silva (Universidade Federal de Santa Maria) \\ Júlio Eduardo Rohenkohl (Universidade Federal de Santa Maria) \\ Júlio César Cossio Rodriguez (Universidade Federal de Santa Maria) \\ Julio Werle Berwaldt (Universidade Federal de Santa Maria)
}

\title{
Instituições e Inovação Tecnológica: Desafios Teórico-Metodológicos
}

Área Temática ABEIN - 5.5 Mudanças técnicas, organizações e instituições Journal of Economic Literature - O31: Innovation and Invention: Processes and Incentives

\section{RESUMO}

Os arranjos para inovação tecnológica são preocupação recorrente na formulação de políticas de fomento à inovação. O presente artigo busca identificar os processos de interação entre agentes nas principais correntes teóricas sobre inovação tecnológica, de forma a propor um modelo de análise de instituições que complexifique a classificação proposta por Richard Scott em sua obra Institutions \& Organizations. Inicialmente, é apresentado o modelo de Tríplice Hélice, apontando a dificuldade de promover uma discussão quanto aos processos de interação entre agentes. Posteriormente, retoma-se a literatura de Sistemas de Inovação, contextualizando a problemática existente na compreensão do papel das instituições na organização dos agentes. Na terceira seção, apresenta-se o modelo de Richard Scott e os problemas para a observação empírica da tipologia proposta. Por fim, o artigo apresenta uma alternativa para operacionalizar os pilares de Scott, de forma a identificar fatores institucionais existentes em um determinado ambiente de inovação.

Palavras Chave: Tríplice Hélice, Sistema de Inovação, Instituições e Organizações

\begin{abstract}
The arrangements for technological innovation are recurrent concerns in the formulation of policies to foster innovation. The present article seeks to identify the processes of interaction between agents in the main theoretical approaches on technological innovation, in order to propose a model of institutional analysis that would complexify the classification proposed by Richard Scott in his work Institutions \& Organizations. Initially, the model of Triple Helix is presented, pointing out the difficulty of promoting a discussion about the interaction processes between agents. Subsequently, the literature on Innovation Systems is reviewed, contextualizing the existing problem in understanding the role of institutions in the organization of agents. In the third section, we present the Richard Scott model and the problems for the empirical observation of the proposed
\end{abstract}


typology. Finally, the article presents an alternative to operationalize the pillars of Scott, in order to identify institutional factors in a given innovation environment.

Keywords: Triple Helix, Innovation System, Institutions and Organizations

\section{Introdução}

Pensar a inovação tecnológica é compreender os caminhos possíveis para o desenvolvimento nacional. Tradicionalmente a inovação tecnológica fora pensada a partir de um modelo linear de inovação, cabendo o financiamento estatal à ciência com vistas a aplicações, à descoberta de princípios básicos que posteriormente seriam absorvidos pela indústria, mediante publicações e desenvolvimento de aplicações de menor custo e incerteza. A contraposição desse modelo linear se deu a partir da hipótese da demanda de mercado, onde as inovações estavam condicionadas a oportunidades que se apresentavam nos setores comerciais, permitindo investimentos externos às firmas a fim de custear o desenvolvimento de novos produtos e processos.

Entretanto, tal visão dicotômica ignora aspectos essenciais das preocupações sociais de uma época. Os interesses de indivíduos e instituições são parte edificante do processo de inovação tecnológica, não sendo este um processo linear ou empreendido de maneira plenamente racional. Em uma sociedade baseada no conhecimento, os fluxos entre setores são altamente volúveis, e a identificação de padrões institucionais contribui para a compreensão da racionalidade e objetivos envolvidos na formulação de decisão dos indivíduos e na construção de uma política de fomento a partir da esfera pública. Há grandes desafios teóricos e metodológicos em avaliar a o processo de inovação de forma integrada, para além dos fatores materiais da dinâmica de transformação produtiva e sistêmica. Quando a tarefa torna-se identificar as instituições envolvidas no processo os desafios são adicionais e envolvem avaliar o que são instituições e quais são as instituições no processo de inovação em perspectiva sistêmica. Dada as dificuldades de definir, identificar e de medir instituições em sistemas em evolução, esforços iniciais exigem clareza sobre o que são instituições e como elas afetam em processos de inovação.

Não obstante o desafio proposto, a abordagem da Tríplice Hélice, que enfatiza a interação dos comportamentos dos atores enquanto constituinte de mecanismos de seleção em ambientes inovativos, tem popularizado o debate sobre os arranjos institucionais para inovação tecnológica. Mais amplamente, alternativas contemporâneas e com caráter de sistemas abertos constituem esforços válidos na direção da compreensão sobre fatores imateriais envolvidos na inovação tecnológica, inicialmente em abordagens evolucionárias, como a dos Sistemas de Inovação. Tais sistemas são identificados por ações articuladas a fim de produzir aprendizagem quanto a produtos e processos, incrementando a capacidade produtiva sem alteração quantitativa dos fatores de produção empregados. Não obstante, tais abordagens sistêmicas ainda apresentam limites na observação sobre aspectos estruturais desses sistemas e a sua conexão com variáveis no nível internacional.

A partir da revisão quanto aos pressupostos das correntes teóricas sobre inovação tecnológica, o texto estará dividido em quatro seções. Na primeira, serão abordados os benefícios e fraquezas metodológicas da abordagem da Tríplice Hélice, argumentando que, por estar centrada em análises de redes, a Tríplice Hélice enfatiza o estudo das unidades e interações, sem aprofundar como tais interações produzem instituições. A segunda parte trata sobre o estudo da inovação de forma sistêmica, retomando a busca de identificação de modelos estruturais em sistemas abertos, mais ou menos complexos; neste caso, a crítica direciona-se à inconsistência conceitual existente na definição de 
"instituição", cuja literatura não compreende uma visão holística quanto aos processos de institucionalização, tanto em estruturas quanto em unidades. A terceira seção continuará os esforços de Richard Scott, na obra "Institutions and Organizations", na versão atualizada em 2008 da obra original de 1995, na busca de um conceito robusto e operacionalizável de instituições, capaz de remediar os pontos fracos da argumentação do autor. Ao fim, será apresentado o modelo de análise de instituições proposto pelos pesquisadores do Grupo de Estudos em Capacidade Estatal, Segurança e Defesa - GECAP.

\section{Como estudar ambientes de inovação de forma complexa: A análise de Tríplice Hélice}

A teoria da Tríplice Hélice tem se popularizado como instrumento analítico de ambientes de inovação. Universidades, agências de fomento, empresas e governos têm se aproximado desta abordagem vinculada às teorias da Administração. De fato, o modelo da Tríplice Hélice contribui grandemente para a compreensão de ambientes inovativos e o papel cumprido neste processo por diferentes atores, sobretudo as Universidades. $\mathrm{O}$ foco nas competências dos atores, os potenciais diferenciados das instituições de pesquisa e as interações não lineares entre estado, empresas e universidades são sem dúvida a grande força da teoria. Muito influenciadas por esta concepção, universidades adaptaram suas políticas de inovação ao adotar programas de transferência tecnológica, estímulo à criação de empresas (incubadoras) e ao relacionamento com o mercado.

Um dos avanços mais importantes do modelo analítico diz respeito a sua compreensão sobre configuração das unidades de um ambiente inovativo. A divisão funcional entre Universidades, empresas e governo remete a suas competências particulares e compartilhadas. Ao contrário de teorias antecedentes, nesta perspectiva são as Universidades que ganham responsabilidades fundamentais no processo inovativo. $\mathrm{O}$ argumento da Tríplice Hélice destaca as oportunidades para que a Universidade desempenhe "a função de participar mais ativamente do processo de desenvolvimento econômico" e apresenta o potencial da universidade enquanto impulsora da competitividade das empresas de determinada região. A tríplice hélice emergiu, assim, como uma maneira de direcionar a pesquisa acadêmica para uma postura mais aberta frente à possibilidade de desenvolvimento de aplicações práticas com explorações comerciais, buscando solucionar os problemas da academia com o direcionamento à pesquisa básica delimitada por disciplinas, sem a capacidade de superar de forma positiva conflitos políticos ou com setores industriais. Nesta linha de raciocínio, o processo de financiamento da pesquisa engendra transformações institucionais a fim de ressignificar a normatividade existente na pesquisa (BENNER; SANDSTRÖM, 2000, p. 293).

Benner e Sandström (2000, p. 297) argumentam ainda que a construção de alianças entre indústria e universidade a partir da mobilidade de pesquisadores e estabelecimento de programas conjuntos se dá com o objetivo de aumentar a competitividade industrial a partir do aumento da oferta de profissionais com níveis de pós-graduação, bem como de integrar a universidade aos objetivos de conhecimento das firmas. A reforma acadêmica vem, portanto, como forma de aprimorar a competitividade corporativa, com a universidade acolhendo as demandas qualitativas e quantitativas da indústria envolvida no processo de construção da tríplice hélice, mas mantendo sua autonomia e rigidez metodológica. Para desempenhar tal função, a existência de instituições que transitem entre as hélices e que identifiquem áreas potencialmente sinérgicas apresenta caráter central, de forma a superar eventuais miopias existentes em setores específicos. 
Neste ponto se situa a segunda grande contribuição teórica do modelo Tríplice Hélice, a saber, sobre os fluxos interacionais dos atores que integram o ambiente inovativo. A tríplice hélice é definida por ligações com caráter institucional entre universidades, indústrias e governo(s), onde as relações são baseadas no conhecimento e, portanto, assumiram um caráter de rede (LEYDESDORFF, 2018, p. 5). De acordo com Leydesdorff e Etzkowitz (1996, p. 279), em um sistema global de relações entre indústria, academia e políticas de Ciência \& Tecnologia, três dinâmicas distintas podem ser observadas: o caráter dinâmico da economia de mercado, as dinâmicas internas do conhecimento necessárias à produção e as interfaces de governança em diferentes níveis. $\mathrm{O}$ crescimento de interações entre organizações é capaz de criar novas estruturas dentro das previamente existentes, a exemplos de centros de pesquisa em universidades ou alianças estratégicas entre companhias. Tais interações também originam redes e organizações híbridas que se inserem na dinâmica complexa da abordagem da tríplice hélice (LEYDESDORFF; ETZKOWITZ, 1996, p. 280).

A tríplice hélice é importante, portanto, de um ponto de vista interacional, cujas mudanças permitem a identificação de novos mecanismos de inovação, como por exemplo as incubadoras tecnológicas, escritórios de transferência de tecnologia e empresas de capital de risco (ETZKOWITZ; DE MELLO; ALMEIDA, 2005, p. 413). Neste âmbito interacional, Dzisah e Etzkowitz (2008, p. 109) identificam 3 elementos chave quanto a adaptação dos fluxos de informação nos arranjos de tríplice hélice, que favorecem a produção de inovações tecnológicas. São eles: (i) necessidade de consenso pelos atores relevantes quanto à identificação de forças e fraquezas em potencial, (ii) necessidade de produção de estudos que identifiquem meios para a superação de barreiras e identifiquem precisamente as oportunidades de mercado e (iii) a formulação de um plano de ação que adapte modelos organizacionais ou crie novos a partir das circunstâncias locais. Reconhece-se, portanto, que as esferas institucionais apresentam importância no desenvolvimento de inovações tecnológicas, porém estas são um resultado da interação e não uma prescrição governamental (DZISAH; ETZKOWITZ, 2008, p. 104).

Ao participar de redes locais sob a organização de tríplice hélice, as firmas podem alcançar novos mercados, reduzir custos a partir do compartilhamento de projetos e recursos para o desenvolvimento de novos produtos e ideias. Em um ambiente de tríplice hélice, a inovação é produto de redes relacionais onde ocorre o compartilhamento de intenções, estratégias e projetos que adicionam valor excedente (ETZKOWITZ; LEYDESDORFF, 2000). O conteúdo da colaboração depende dos representantes dos setores na instituição integradora, sobretudo quando se trata das firmas/setor privado. Enquanto firmas pequenas ou estágios iniciais se beneficiam do conhecimento e do acesso aos mercados, as firmas grandes podem se aproveitar da possibilidade de construção de cadeias efetivas de fornecimento. A inovação está diretamente ligada à capacidade de fomentar atividades de integração entre as hélices, engendrando legitimidade e autoridade (ELVEKROK et al., 2017). A inovação colaborativa ocorre quando os atores são capazes de superar as fronteiras tradicionais de suas áreas de pesquisa, oferecendo sua expertise e integrando equipes multidisciplinares a fim de desenvolver ideias, produtos e processos.

No entanto, a despeito da sua popularidade contemporânea, a Teoria da Tríplice Hélice limita seu foco às partes internas de sistemas de inovação complexos. Seu enfoque no espaço interacional, sugere que a inovação é consequente de mecanismos que promovem a interação entre os atores. Embora avance na compreensão da configuração das unidades e fluxos interacionais, sua perspectiva processual limita a observação de aspectos sistêmicos mais estruturantes, tais como instituições ambientais cognitivas, regras de governança estruturadas, estruturas sistêmicas de poder e níveis de análise superiores ao local. Embora a perspectiva da Tríplice Hélice sugira que a sobrevivência 
da colaboração se dê a partir da construção de relacionamentos, que podem estar baseados na liderança, confiança, transparência, motivação, competência e equidade (JEROME, 2011, p. 14), carece de um conceito claro de instituições para a viabilização de observações práticas sobre o papel de aspectos imateriais e materiais na construção de relacionamentos que habilitem a produção de inovações tecnológicas a partir de perspectivas multidisciplinares.

Há uma grande variedade de enfoques teóricos nas ciências sociais que abordam instituições (SCOTT, 2013; RUTHERFORD, 1984; HODGSON, 2006). Dentro do amplo espectro, há variações de significado nada triviais, as quais alteram as análises. Por exemplo, a abordagem da Nova Economia Institucional enfatiza uma racionalidade de antecipação de consequências de regulações sociais e econômicas. Seu posicionamento epistêmico é muito diferente de uma teoria evolucionária vebleniana que privilegia o compartilhamento de hábitos de pensar nas interações entre atores. Uma outra variante considera que a normatividade implica a constituição de identidades dos atores sociais que agem segundo o constrangimento de valores sociais. Nesta medida, uma teoria de interações sistêmicas que deixa de referir as bases conceituais das instituições também deixa vago como se dão e como se avaliam as interações.

$\mathrm{O}$ foco em uma lógica fluida e integrada de relações acaba por ignorar assimetrias entre atores e instituições mais complexas do que simples arranjos de governança. As hélices são, portanto, mecanismos de seleção, que respondem a interações entre os atores componentes destas, com a premissa de que a criação de redes trilaterais construa uma sociedade global do conhecimento (LEYDESDORFF; ETZKOWITZ, 1996, p. 284). Tal definição carrega uma grande carga de normatividade, evidenciada por Dagnino (2004, p. 256-257), argumentando que a Tríplice Hélice privilegia a lógica de mercado na relação entre empresa e universidade. Esta lógica é diversa à que ocorre em alguns setores específicos, tais como o de produtos de Defesa. ${ }^{1}$ A seleção de produtos de Defesa combina elementos de mercado, como custos e preços, com outros extra-mercado, como a geopolítica que retarda a difusão de muitas tecnolgias pelo seu poder dissuasório na disputa política e militar entre países. O alinhamento de compreensão dos problemas e de interesses de um Estado que adota a economia de mercado e as empresas que atuam no mercado é parcial. Adicionalmente, Leydesdorff e Etzkowitz (1996, p. 280-281) minimizam a importância de instituições cognitivas (valores compartilhados entre produtores e consumidores), reduzindo a construção de confiança mútua ao conceito de governança, expresso por eles enquanto uma intrincada estrutura de controles reflexivos. Tais controles reflexivos constituem mecanismos de seleção de uns atores para com os outros, com a endogeneização de contingências e ações intencionais, a fim de perpetuar a existência do sistema complexo através da recombinação de suas partes. ${ }^{2}$

\footnotetext{
${ }^{1} \mathrm{O}$ investimento em P\&D militar, por exemplo, pode engendrar a criação de novas organizações de pesquisa relativas à ciência e engenharia, impulsionando a inovação tanto enquanto desenvolvimento de produtos de defesa quanto de tecnologia em aplicações civis. A partir de spin-offs e contratos de desenvolvimento, legitima-se o investimento e reduzem-se as incertezas envolvidas no processo de inovação tecnológica, que tende a decair à medida que as tecnologias amadurecem e têm sua demanda estabilizada (MOWERY, 2009, p. 457). Dagnino (2004, p. 256-257) argumenta que a partir de tal preponderância, há um "processo de cooptação da comunidade de pesquisa", direcionando-a ao suprimento das demandas do mercado.

${ }^{2}$ A fraqueza conceitual na abordagem da tríplice hélice está na indefinição sobre o papel que o Estado deve assumir enquanto "motor" da produção de inovações tecnológicas. Observa-se que a maior causa deste problema se dá pelo não aprofundamento quando se tratam de aspectos exógenos à interação: As convencionais burocracias públicas e privadas são delimitadas a fím de resolver problemas pontuais e de forma vertical, mediante programas e políticas administrados centralmente (JEROME, 2011, p. 9). Identifica-se então a dificuldade da abordagem da tríplice hélice em lidar com questões como como instituições ambientais, regras de governança, análise de fatores cognitivos e estruturas sistêmicas de poder.
} 
A abordagem da tríplice hélice apresenta um caráter sistêmico, mas insere-se em um patamar prévio à abordagem da complexidade por não prover uma explicação abrangente quanto aos processos envolvidos na construção de estruturas, interações e unidades capazes de promover a inovação tecnológica, apresentando enfoque no conhecimento dos membros sem que haja um planejamento coerente para a aplicação deste na produção de inovações. Os benefícios da organização em rede acabam apresentando-se como fins em si mesmos e resultando em um trade-off entre colaboração e conhecimento, permeando as interações entre hélices e constrangendo o processo de inovação tecnológica. Dessa forma, um retorno às perspectivas estruturais de sistemas de inovação (aspectos políticos/regulatórios, cognitivos e normativos), em perspectiva complexa e aberta (níveis diferentes de análise e funcionamento), pode produzir instrumentos analíticos mais claros sobre o papel amplo desempenhado pelas instituições em processos de inovação.

\section{Como estudar ambientes de inovação de forma sistêmica: a literatura de Sistemas de Inovação}

Teorias sobre o processo de inovação têm voltado o seu foco para os processos de interação entre atores envolvidos no fenômeno, de forma a avaliar casos de sucesso ou fracasso. É o caso da literatura sobre Tríplice Hélice apresentada previamente. A presente seção enfatiza o papel da recuperação e aprofundamento as teorias sistêmicas, a fim de compreender as diferenças de complexidade e níveis analíticos. À exemplo da seção anterior, serão apresentados a literatura base para a construção do conceito, e os desafios da abordagem apresentada, sob a ótica da necessidade de estabelecimento de ferramentas com robustez metodológica a fim de identificar o papel das instituições na organização de sistemas de inovação.

A literatura sobre o caráter sistêmico da inovação surge a partir da década de 1980 como contraponto à noção linear previamente existente e voltando a atenção para o papel da interação dos agentes mediante práticas de aprendizado e investimento. Segundo Cassiolato, de Matos e Lastres (2014), a emergência da abordagem sistêmica suporta a abordagem estruturalista, em que a existência de inovações é constrangida pelas diferenças entre os países, sendo a intervenção governamental mecanismo necessário para promover as mudanças estruturais necessárias à superação do subdesenvolvimento. $\mathrm{O}$ argumento dos autores para sustentar a dimensão "nacional" dos sistemas de inovação se dá pela centralidade dos esforços locais na seleção, compra, uso e transformação das tecnologias.

Neste momento introdutório, cabe apresentar, conforme Cassiolato e Lastres (2005, p. 35-36), a transformação ocorrida quanto à percepção das etapas do processo de inovação tecnológica, que passou a ser visualizado de forma "não linear, cumulativa, específica da localidade e conformada institucionalmente". Posteriormente, incorporouse também o papel de externalidades ao comportamento das firmas, tanto sob a forma de engenharia reversa quanto pela difusão do conhecimento entre diferentes setores da cadeia de produção e da universidade.

A ideia básica do conceito de sistemas de inovação é que o desempenho inovativo depende não apenas do desempenho de empresas e organizações de ensino e pesquisa, mas também de como elas interagem entre si e com vários outros atores, e como as instituições - inclusive as políticas - afetam o desenvolvimento dos sistemas. (CASSIOLATO; LASTRES, 2005, p. 37) 
Cassiolato e Lastres (2005, p. 41) também discutem o direcionamento de mercados das firmas envolvidas no processo de inovação, onde "produtores locais, que operam em cadeias globais, encontram barreiras significativas para desenvolver capacitação inovativa e cadeias integradas em âmbito nacional". Em contraposição, os autores ainda afirmam que empresas voltadas aos mercados locais apresentam maior possibilidade de desenvolvimento de capacidades não trabalhadas por empresas voltadas à exportação.

A função de um sistema de inovação é gerar, difundir e utilizar tecnologia, tanto como artefatos físicos quanto como conhecimento técnico. A realização destas tarefas pelas partes constituintes é o que caracteriza as capacidades, enquanto competências econômicas, do sistema de inovação (CARLSSON et al., 2002, p. 235). Segundo Johnson e Lundvall (1994, p. 698), um sistema de inovação consiste em (i) uma estrutura de produção, marcada por processos de aprendizagem em uma relação auto fortalecedora, (ii) uma organização institucional, composta pelas rotinas, normas, leis e regras que determinam os comportamentos e relações pessoais ${ }^{3}$.

A abordagem sistêmica pode ser aplicada de maneira adequada em três níveis de análise, em sistemas construídos a partir de: (i) uma tecnologia enquanto um campo do conhecimento, (ii) um produto ou artefato e (iii) um conjunto de produtos e artefatos que almejam realizar determinada função. No primeiro caso, o enfoque está no papel que uma tecnologia exerce a partir de sua utilização em diferentes produtos, à exemplo da tecnologia de micro-ondas e do processamento de sinais digitais. No segundo caso, enfatiza-se a relação do produto com os seus consumidores, enquanto no terceiro analisam-se os atores e instituições participantes do sistema enquanto ofertantes do conjunto de produtos, compreendendo também os produtos complementares ou substitutos. As fronteiras do sistema, as redes, instituições e atores envolvidos variam de acordo com o nível de análise (CARLSSON et al., 2002, p. 237-238)

Lidar com as características dinâmicas de um sistema implica levar em conta as alterações no conteúdo das tecnologias e produtos (CARLSSON et al., 2002, p. 240). A noção incremental de inovação também deve ser parte integrante desta análise, que ainda segundo Carlsson et al. (ibid) tem sua viabilidade condicionada ao desenvolvimento e capacidade de incorporação de tecnologias complementares. Para o autor, a análise de sistemas dinâmicos, quando feita de forma histórica, pode incorrer na necessidade de redefinição de suas fronteiras à medida que se dá sua evolução. Em uma revisão quanto aos componentes do Sistema Nacional de Inovação, referindo-se ao caso estadunidense, Mowery (2009, p. 456) identifica como componentes deste as instituições responsáveis pelos processos e fontes de financiamento de $\mathrm{P} \& \mathrm{D}$, bem como as políticas públicas que afetam o desenvolvimento tecnológico: política antitruste, propriedade intelectual, treinamento de cientistas e engenheiros, bem como a adoção de tecnologias.

A noção de "Sistemas de Inovação" pode compreender três conceitos: (i) os Sistemas Nacionais de Inovação, focado nas firmas, universidades, escolas profissionalizantes, institutos de pesquisa, governo e nas relações entre estes, apresentando uma delimitação geográfica na qual se dá o compartilhamento de cultura, história, linguagem e institucionalidade; (ii) os Sistemas Tecnológicos, cuja ênfase se dá em tecnologias ou em indústrias específicas, bem como nos fluxos de conhecimento existentes dentro destes; e, por fim (iii) os Sistemas Setoriais de Inovação, que enfatizam as firmas enquanto desenvolvedoras de produtos e competidoras que consideram o papel do ambiente de seleção, com a delimitação das fronteiras do sistema dependentes de

${ }^{3}$ Os autores alertam quanto aos perigos do caráter predominantemente estrutural existente em tal abordagem, apresentando a recuperação da racionalidade conflitiva enquanto instrumento de mudança deliberada pela ação humana. (JOHNSON; LUNDVALL, 1994, p. 698) 
aspectos competitivos, interativos e organizacionais, superando dimensões puramente geográficas (BRESCHI; MALERBA, 2005, p. 130-131).

A definição de Sistemas Setoriais de Inovação encontra respaldo na obra de Rennstich (2008, p. 175), afirmando que as rivalidades em um ambiente caracterizado principalmente por redes externas serão marcadas, sobretudo, pela competição cooperativa. Isto significa dizer que os atores deverão trabalhar para encontrar um equilíbrio quanto à competição que estão dispostos a tolerar e a cooperação necessária para a não erosão de suas posições econômicas e sociais. Em um caráter normativo, tal posicionamento racional seria capaz de mitigar o engajamento em rivalidades estratégicas, principalmente em setores que apresentam maior interdependência. Em contraste, a competição hostil em setores industriais tradicionais, vinculados ao modelo linear de inovação e com raízes na indústria de defesa apresenta um claro desafio às perspectivas transformadoras que se utilizam das tecnologias de informação e comunicação enquanto maneira de superar fronteiras geográficas.

Arrighi (1997, p. 20) argumenta que as inovações econômicas estão temporariamente agrupadas em função do arranjo social em que ocorrem, e a especialização das instituições constitui uma força conservadora a ser vencida: Estados fornecem proteção à propriedade privada, domicílios fornecem força de trabalho e empresas fornecem meios para a realização das funções das duas instituições prévias, bem como insumos para a realização das funções de demais empresas. No nível mais amplo, as relações entre Estados, instituições de finalidade semelhante, conferem a estes a soberania e a constituição de uma interdependência global a partir de regras e normas capazes de constranger a tomada de decisão e conferir certo grau de previsibilidade ao funcionamento do sistema.

Arrighi (ibid) discorre subsequentemente que a inovação do sistema de acumulação capitalista está na busca de estabilidade das operações das empresas no comércio de meios para proteção e subsistência, mas, que em um contexto de concorrência, reproduzam a lógica Schumpeteriana e busquem novas combinações de insumos e produtos a fim de obter lucros extraordinários. Tais inovações englobam novos métodos de produção, novas commodities, novas fontes de fornecimento, novos mercados e rotas comerciais e, por fim, novas formas de organização. (ARRIGHI; SILVER; BREWER, 2003, p. 16)

Discorrendo sobre modelos de desenvolvimento econômico com viés Schumpeteriano ${ }^{4}$, Arrighi, Silver e Brewer (2003) apresentam as inovações como processos espacialmente estruturados, que dão origem a Estados mais ou menos desenvolvidos ${ }^{5}$; De acordo com Schumpeter, empreendimento é a realização de novas combinações dos meios de produção $(1997$, p. 83). O mecanismo estrutural não opera em um vácuo ideológico, sendo influenciado por crenças e teorias quanto à busca pela riqueza nacional, direcionando os esforços desenvolvimentistas de países atrasados no processo de acumulação de capital em uma economia em constante movimento.

A indefinição quanto à identificação de um consenso nas fronteiras dos Sistemas de Inovação são um ponto fulcral no debate. Arrighi e Rennstich argumentam que o processo de inovação tecnológica e construção das economias nacionais estão vinculados a um sistema e à construção da hegemonia, com um novo ciclo sistêmico dependente da "destruição criativa" advinda de um processo inovador de acumulação de capital. A

\footnotetext{
${ }^{4}$ Leia-se o modelo do "Ganso voador" de Akamatsu e o modelo do "Ciclo do Produto", de Vernon

${ }^{5}$ Ao passo que a acumulação de capital proporcionada aos Estados no centro do processo de inovação também cria condições para que se desenvolvam tanto o ambiente quanto os fatores de trabalho adequados à incorporação de inovações futuras, mesmo que estas se dêem em ambiente exógeno às suas fronteiras nacionais (ARRIGHI; SILVER; BREWER, 2003, p. 18).
} 
literatura de inovação precisa enfatizar a observação de desafios internacionais ${ }^{6}$, bem como a dificuldade para observação de desafios estruturais dada a aceitação dos discursos que moldam a estrutura do sistema internacional.

Lundvall (2007) argumenta que a relação entre inovação e crescimento econômico está relacionada não somente à infraestrutura de $C \& T$, mas também às instituições e organizações que sustentam a construção de competências em mercados, ambientes de trabalho e na educação. Neste ínterim, a abordagem de Tríplice-Hélice se apresentou como alternativa completa aos Sistemas de Inovação, mas seu enfoque demasiado no papel da ciência e das universidades na inovação limitou a compreensão quanto ao papel do conhecimento tácito e do aprendizado organizacional na produção de inovações.

Mowery (ibid) e Soete, Verspagen e Weel (2010, p. 1164) argumentam que, apesar da ênfase na visão holística dos fatores que afetam a inovação, o conceito de Sistema Nacional de Inovação ainda não dispõe de consenso quanto à sua definição, que possibilitaria sua avaliação a partir de instrumentos metodológicos coerentes. Esta perspectiva crítica vai ao encontro do que afirma Lundvall (2007), que considera que, apesar da ampla aplicação do conceito de "Sistemas de Inovação" a partir da versão original de Christoper Freeman, esta ocorreu de forma limitada, com enfoque demasiado na inovação em infraestruturas formais e setores de alta tecnologia.

Sistemas de inovação pecam no nível de análise: apesar da evolução conceitual, de sistemas locais para sistemas nacionais, ignora-se o nível internacional, constituído por um conjunto maior, que engloba as dinâmicas e estruturas de inovação dos sistemas de inovação a partir da interação entre partes análogas. Entretanto, a literatura de Sistemas de Inovação dá um passo importante ao considerar as diferenças no acesso às tecnologias e na competência para utilização destas por diferentes agentes. (LUNDVALL, 2007, p. 20). Ao enfatizar os processos de aprendizado em um contexto de agentes racionalmente limitados, as interações e instituições envolvidas apresentam-se como variável interveniente na produção de inovações e competências, mas como estudar o papel das instituições na inovação tecnológica?

\section{Como compreender instituições e sua complexidade?}

Durante a década de 1990, os economistas que pressupunham leis universais de funcionamento dos sistemas econômicos desconsideraram, em grande parte, os contextos políticos e institucionais locais. Esta análise apressada tendeu a tomar alguns mecanismos institucionais como garantidos em qualquer país observado como economia de mercado: (i) um sistema funcional para direitos de propriedade, (ii) um aparato regulatório capaz de mitigar as possibilidades de fraudes e de comportamentos nocivos à competitividade,(iii) um nível moderado de coesão social, (iv) um conjunto de regras políticas capazes de diminuir os riscos e mediar conflitos sociais e, por fim, (v) a existência de mecanismos anticorrupção. No entanto, países subdesenvolvidos que adotaram reformas para contemplar este pacote nem sempre alcançaram crescimento econômico sustentado. A ligação entre preceitos de uma economia de mercado e as instituições estruturadoras dos mercados se mostrou mais variada e complexa (RODRIK, 2007, p. 1, 3 e 153).

\footnotetext{
${ }^{6}$ Arrighi, Silver e Brewer (2003, p. 7) identificam a industrialização como um processo cujos custos são preteridos em função dos benefícios esperados. Dentre os custos, os autores enumeram a poluição do ar e água e a potencial destruição da zona rural; bem como conceitos sociológicos como a "alienação" Marxista, a "gaiola de ferro" Weberiana e a "anomia" de Durkheim. Arrighi (1997, p. 208) também explicita a necessidade de desvinculação entre "desenvolvimento" e "industrialização", com o primeiro termo tendo uma significação mais ampla juntamente à diminuição entre as distâncias entre "riqueza, poder e bem-estar".
} 
A complexidade das instituições estruturantes dos mercados decorre de duas fontes principais. A primeira provém de seu enraizamento em uma instância política nacional confrontada com um processo de globalização financeira e produtiva que gera lógicas de interação internacionalizadas. Há um enfrentamento de institucionalidades locais com outras supranacionais. Embora muitos países tenham adotado padrões globalizados de interações comerciais, produtivas e de propriedade intelectual, por exemplo adentrando a Organização Mundial do Comércio (OMC) e inserindo firmas em cadeias globais de valor, houve reações assimétricas de desempenho econômico. Isto sinaliza que o plano da institucionalidade nacional tem consequências para o crescimento econômico (RODRIK, 2007, p. 2).

A segunda decorre do fato de que muitas instituições que regem os mercados não são exclusivas dos mercados. Isto significa que há sobreposições de propósitos e a coordenação institucional da interação entre agentes não é perfeita. Por exemplo, o direito de propriedade pode conflitar com outros requisitos fundamentais para a sustentação da ordem social como o direito à vida. Uma outra situação a considerar é que a estruturação do Estado não atende apenas a eficiência de arrecadação de impostos, mas também a legitimação exercício do governo. A economia de mercado está imersa em instituições que regem outras instâncias da vida em sociedade (RODRIK, 2007, p. 154-155).

A existência de particularidades regionais e nacionais, manifestas a partir de diferenças consideráveis na capacidade das universidades em transmitir conhecimento e dos empreendimentos locais em absorver o conhecimento e aproveitar oportunidades de mercado demonstram a necessidade de flexibilidade na compreensão do papel de diferentes atores e das idiossincrasias do aparato institucional (ELVEKROK et al., 2017, p. 3, RODRIK, 2007, p. 5). Este fenômeno se repete em escalas menores, dada a dificuldade de diálogo entre pesquisadores de diferentes áreas, seja em consequência das especificidades do linguajar científico de cada especialização, enfraquecendo a comunicação e o consequente intercâmbio de informações que poderia levar à identificação de oportunidades de pesquisas colaborativas e inovação tecnológica (JEROME, 2011, p. 13).

Tal percepção crítica vai ao encontro ao objetivo do presente trabalho, onde identifica-se uma abordagem redundante do conceito de instituições, que não apresenta uma definição clara e operacionalizável quanto aos aspectos políticos, regulatórios, cognitivos e normativos. Por exemplo, compreender instituições pela ótica de Douglass North como "Regras do jogo", conforme adotado por Rodrik $(2007$, p. 8) tem implicações para as investigações completamente distintas de considerar instituições como hábitos de pensar compartilhados, conforme a linha Vebleniana. Do mesmo modo, tal indefinição apresenta obstáculos à realização de observações empíricas a nível internacional, retomando as dificuldades quanto às definições de fronteiras expressas previamente na caracterização do conceito de sistemas de inovação. A abordagem sistêmica é, portanto, dependente da capacidade doméstica de desenho e articulação institucional, e, para o aprimoramento destas, é necessário empreender um esforço em prol da possibilidade de avaliação da capacidade de agência das instituições, a fim de identificar os mecanismos institucionais adequados à promoção do desenvolvimento a partir dos fatores econômicos disponíveis.

A economia de mercado está necessariamente incorporada em um conjunto de instituições que não respondem à lógica do mercado. Isto quer dizer que os mercados requerem instituições pois não surgem, regulamentam-se, estabilizam-se ou legitimam-se de maneira autônoma (RODRIK, 2007, p. 155). Em um viés institucional, as funções e atividades sobrepõem as características individuais, visto que podem ser distribuídas entre diversos atores e permitindo sua recombinação em novas formas, induzindo a cooperação 
mesmo entre variações de agendas e interesses. Os empreendedores institucionais podem encarregar-se da angariação de suporte em ambientes mais amplos que o institucional de forma a demonstrar amplamente os benefícios da associação institucional - bem como de transformar o ambiente de trabalho em uma instituição já existente (SCOTT, 2013, p. 117).

As instituições apresentam-se como produtos de estruturas de poder, seja este político, material ou simbólico. Sua gênese se dá a partir da incorporação de processos reguladores, valores normativos e compartilhamento de cognições. Embora construídas e sustentadas pela participação de atores individuais, as instituições assumem caráter próprio a partir da estruturação de um sistema, fornecendo estabilidade e propriedades que confiram propósito aos atores nelas inscritos (SCOTT, 2013, p. 57). A definição de instituições também deve englobar as associações com comportamentos e recursos materiais, de maneira a elucidar as assimetrias de poder existentes dentro destas e permitir a observação tanto de restrições legais, morais e culturais quanto de empoderamento das ações individuais dos membros (SCOTT, 2013, p. 58).

No terceiro capítulo sua Institutions and Organizations, Richard Scott empreende uma vasta revisão bibliográfica quanto às definições do conceito de "instituição" dentro das ciências econômicas, ciências sociais e ciências políticas, culminando na elaboração de uma tríade de pilares tipológicos capazes de congregar similaridades entre as abordagens específicas de cada autor. Scott identifica mecanismos de conformidade, ordem, lógica, indicadores, efeitos e bases de legitimidade em cada um dos pilares, que serão apresentados a seguir.

O primeiro pilar apresentado por Scott é o pilar regulativo (2013, p. 59-64), que enfatiza os processos regulatórios, especificamente: estabelecimento de regras, monitoramento e sancionamento de atividades - sob a forma de recompensas ou punições - enquanto meio para condicionar o comportamento futuro. Em um sistema com regulamentações estáveis, os atores se comportam de maneira racional e adotam uma lógica instrumental: as regras são estabelecidas a fim de atingir benefícios ou evitar punições por meio da atuação dentro da instituição, ao passo que sua estabilidade permite o cálculo quanto às vantagens e desvantagens da adoção das regras institucionalizadas.

Em um segundo momento, Scott apresenta o pilar normativo ${ }^{7}$ (2013, p. 64-66), cuja ênfase se dá nos valores ${ }^{8}$ e normas ${ }^{9}$. Neste pilar, presta-se atenção especial aos papéis desempenhados pelos atores em sua especificidade, onde estes apresentam diferentes atividades e metas de acordo com sua natureza e podem tanto construir - via interação ou socialmente - quanto internalizar os constrangimentos ao comportamento social. A centralidade da dimensão normativa se dá na influência estabilizadora das instituições para o estabelecimento de crenças sociais e normas, que seriam a base para uma ordem social estável.

Por fim, o pilar cognitivo (SCOTT, 2013, p. 66-70) é o que apresenta mais similaridades com as perspectivas neoinstitucionalistas dentro da sociologia e estudos organizacionais, dado que confere centralidade às concepções compartilhadas que constituem a natureza da realidade social e engendram a estrutura a partir da qual os significados são construídos. Estas estruturas definem tanto os fins almejados quanto os

\footnotetext{
${ }^{7}$ A principal diferença quanto ao pilar regulativo se dá pela observação de menor agência em três dimensões: obrigação, enquanto subordinação do comportamento ao escrutínio dos demais atores; precisão, enquanto especificidades das condutas requeridas; delegação, enquanto autoridade de terceiros para aplicação de regras e solução de contendas (SCOTT, 2013, p. 60)

${ }^{8}$ Concepções sobre o que é preferido ou desejável frente à construção de padrões que possibilitem a comparação e avaliação de estruturas e comportamentos

${ }^{9}$ Como as coisas devem ser feitas; estabelecimento de meios legítimos para concretização de fins valiosos
} 
meios empregados pelos atores, podendo estes variar em tempo e local. Em suma, o pilar cognitivo diz respeito ao processo de definição de significados comuns dentro de uma estrutura social.

Tomando os três pilares no processo de construção institucional, os aspectos regulativos, quando vistos de maneira transparente e racional, refletem a extensão para qual certos arranjos e procedimentos sociais foram delimitados, servindo para construção de autoridades coletivas ou para aprimorar a tomada de decisão. No pilar normativo, apesar da evolução das normas através de interações que não necessariamente carreguem tal propósito, diferentes atores podem se associar a fim de harmonizar e tornar mais transparente o processo decisório. No pilar cognitivo, os elementos também podem resultar de processos de escolha racionais, consequências de interações coletivas ou disseminados a partir de autoridades culturais institucionalizadas (SCOTT, 2013, p. 118119).

A partir destes pilares, Scott $(2008$, p. 48$)$ propõe uma definição abrangente de instituições. Instituições são composições de elementos regulativos, normativos e culturalcognitivos que, conjuntamente com as atividades e os recursos associados, provêm estabilidade e significado para a vida social. Atividades e mecanismos associados são os sistemas simbólicos, os sistemas relacionais, rotinas e artefatos (Scott, 2008, p. 49, 79 e 140). Eles auxiliam a difusão e a manutenção das instituições.

Tradicionalmente, a mudança institucional foi caracterizada como um problema de mudanças nas tecnologias, estruturas ou habilidades dos empregados, em detrimento da dependência quanto aos valores, normas e obrigações, tanto dos agentes quanto dos sujeitos da mudança. Na perspectiva dos sujeitos, a mudança pode ser necessária, esperada ou desejada, e a partir de tais mecanismos causais, os pilares regulativo, normativo e cognitivo de Scott (2008) tornam-se ferramentas interessantes para a análise do processo (PALTHE, 2014, p. 59).

Para Thelen (2003, p. 212), se as instituições repousam e refletem sobre um determinado alicerce - seja ele baseado na eficiência, no poder ou na cultura - suas mudanças devem ocorrer a partir de mudanças nestas condições principiantes. As perspectivas que apresentam enfoque na dependência da trajetória propõem a hipótese que os fatores responsáveis pelo surgimento de uma instituição não são necessariamente responsáveis pela perpetuação desta, sendo agência, escolhas e contingências variáveis condicionantes para a mudança institucional. A autora apresenta a mudança institucional como produto de um choque exógeno, capaz de perturbar o arranjo vigente e permitindo observar as diferenças entre regiões dadas as especificidades de suas trajetórias políticas.

Os processos de institucionalização compreendem mecanismos de criação e para a difusão e a manutenção de instituições. Scott (2008, p. 122 a 128) apresenta três mecanismos de institucionalização. O primeiro seria o de retornos crescentes que impliquem uma trajetória path dependent de interações entre agentes, gerando efeitos de lock-in em ambientes institucionais que não seriam necessariamente os melhores. Este mecanismo teria sido identificado por Douglass North em analogia com os retornos crescentes de tecnologias difundidas, conforme os estudos de David (1985) e Arthur (1994). Este mecanismo de institucionalização operaria em sintonia com o pilar regulativo porque os retornos seriam percebidos pelos agentes como sanções positivas e permitiriam comportamentos instrumentais, limitadamente racionais.

Um segundo mecanismo de institucionalização seria o de comprometimentos crescentes, operando como complementação do pilar normativo. Através de contratos de relação entre as partes, símbolos e ideologias desenvolvidos pelas organizações vão surgindo relações de reciprocidade e de confiança que constrangem o comportamento dos 
indivíduos a padrões regulares de interação. Aqui desdobra-se o papel das identidades na institucionalização (SCOTT, 2008, p. 123 a 125).

A crescente objetivação é o terceiro mecanismo de institucionalização. Através de um compartilhamento de ideias, há um processo de consenso que alcança um patamar de objetivação de rotinas de interação a ponto de serem encaradas como soluções naturalizadas. Sua propagação ocorre primordialmente por imitação. A objetivação está em sintonia com o pilar cultural-cognitivo das instituições (SCOTT, 2008, p. 125 a 128).

$\mathrm{O}$ reconhecimento e a conformação às pressões no contexto institucional engendram apoio social e garantem a sobrevivência de organizações, à medida que geram identificações de comportamento junto ao ambiente em que se inserem. As organizações não necessitam somente força de trabalho, capital, conhecimento e matéria prima, mas também a aceitação da sociedade que as circunscreve (PALTHE, 2014, p. 62). O condicionamento ao meio em que se inserem as organizações remete aos dilemas na delimitação de fronteiras de Sistemas de Inovação, apresentadas previamente, dado que não somente as firmas precisam adaptar-se ao contexto de multiplicidade de mercados e culturas, mas também o próprio ambiente institucional precisa estar pronto para passar por processos de mudança que permitam a formulação de respostas adequadas no nível unitário.

A classificação de Scott, apesar de elucidar quanto aos componentes institucionais, é de difícil aplicação frente a um cenário empírico, não contrapondo visões contrastantes ou incompatíveis. Ademais, a simples classificação de modelos institucionais em pilares não permite, por si só, a identificação de processos de mudança institucional. "Se as instituições residem e refletem uma fundação particular (seja pela eficiência, relações de poder ou cultura), então elas podem transformar-se em função de alterações em suas fundações" (THELEN, 2003, p. 212). A criação de ambientes inovadores passa pela mobilização de recursos capazes de engendrar coesão e objetivos claros. Para tanto, devem convergir as missões dos atores, suas estruturas e processos, a gestão dos recursos humanos e os mecanismos de incentivos e recompensas a estes; de maneira a diminuir os custos de comunicação, cooperação, coordenação e colaboração, bem como afastar mentalidades conservadoras quanto à natureza transformadora da criação de inovações tecnológicas. $\mathrm{O}$ enfoque da análise precisa ser menos voltado à tecnologia e mais aos processos envolvidos na consolidação das relações cooperativas (JEROME, 2011, p. 18).

Em seu trabalho quanto às mudanças institucionais em ambientes de tríplice hélice, Benner e Sandström (2000, p. 292) tentam conciliar os pilares de Richard Scott (2013). O trabalho dos autores se volta à identificação de mecanismos institucionais que fortaleçam ou constranjam novas formas de produção de conhecimento. Segundo estes, as esferas política, industrial e acadêmica, que compõem a tríplice hélice, convergiram na formação da "economia do conhecimento". Este processo culminou na integração de interesses industriais e políticos ao modelo de avaliação, organização e desempenho da pesquisa acadêmica. Entretanto, os autores argumentam que faltam mecanismos capazes de especificar os relacionamentos entre indivíduos, organizações e instituições.

Benner e Sandström reconhecem os pilares de Scott como explicações valiosas para os processos de institucionalização. Em seu objeto de análise, o financiamento à pesquisa, são observados os pilares regulativo, normativo e cognitivo em três mecanismos: o primeiro diz respeito à alocação de recursos e à necessidade de transparência. O segundo está ligado à conduta profissional dentro da universidade (à exemplo da revisão por pares de publicações). O terceiro, por sua vez, corresponde à importação de estruturas organizacionais de órgãos semelhantes bem-sucedidos, a fim de lidar com a responsabilidade frente às agências de fomento, estruturas políticas e interesses industriais. Os autores tentam apresentar os pilares, relacionando-os com 
práticas e normas observados no financiamento acadêmico, mas o fazem pela mera descrição, não fornecendo mecanismos pelos quais a presença de um determinado pilar possa ser mensurada e comparada com outros casos.

O modelo aqui proposto lida com a necessidade de instanciação e transformação dos pilares em variáveis mais ou menos operacionalizáveis, de forma a avaliar o surgimento e transformação de instituições tanto a nível unitário quanto estrutural. No primeiro caso, propõe-se que a análise diga respeito a observação e mensuração de parâmetros de (i) obediência, definida enquanto respeito às instituições, decorrente da credibilidade e viabilidade das penalidades frente à possibilidade de defecção; (ii) utilidade, definida enquanto o consentimento decorrente do custo-benefício derivado da aceitação da ingerência institucional e (iii) afetividade, identificada pelo compartilhamento de interesses, ideias e valores.

No nível estrutural, propõe-se que os pilares de Scott sejam divididos em fatores institucionais, de forma a permitir a mensuração de maior ou menor presença de uma determinada característica na estruturação institucional. No pilar regulativo, propõe-se mensurar a autonomia e a autoridade, prestando atenção ao tratamento dado a segunda, de forma a não incorrer no erro de tratá-la como concentração de poder, mas sim como um vetor promotor da institucionalização. No pilar normativo, os fatores a serem analisados seriam a aquiescência e a consequência, de forma a identificar a conformidade dos agentes com as normas e regras existentes no ambiente institucional. No pilar cognitivo, os fatores são a coerência e a convergência. É importante explicitar a diferença entre aquiescência e convergência, de forma a delimitar as fronteiras dos pilares normativo e cognitivo: enquanto a primeira diz respeito ao consentimento quanto ao aparato normativo institucional, a segunda se refere ao compartilhamento de interesses sem que este dependa de um ambiente institucional formalizado para consolidar-se.

Procurando aferir a capacidade do Polo de Defesa de Santa Maria (RS) para fomentar inovações a partir de esforços de interação entre Estado (Prefeitura e Forças Armadas), universidades (federal e privadas) e empresas, Florio (2018) aplicou questionário semi-estruturado aos atores participantes do referido Polo. Entre as inquirições estava a avaliação das categorias autonomia, autoridade, aquiescência, consequência, coerência e convergência como variáveis linguísticas moduladas com adjetivos de intensidade - alta, média ou baixa -. As respostas foram agrupadas por frequência.

Os resultados apontam clivagens entre os pilares intitucionais do Polo. A maioria dos respondentes entendeu haver alta autononomia, autoridade e aquiescência. No entanto, a consequência obteve frequência elevada e idêntica entre si nos estratos média e baixa, a coerência obteve frequênciaNo nível estrutural, propõe-se que os pilares de Scott sejam divididos em fatores institucionais, de forma a permitir a mensuração de maior ou menor presença de uma determinada característica na estruturação institucional. No pilar regulativo, propõe-se mensurar a autonomia e a autoridade, prestando atenção ao tratamento dado a segunda, de forma a não incorrer no erro de tratá-la como concentração de poder, mas sim como um vetor promotor da institucionalização. No pilar normativo, os fatores a serem analisados seriam a aquiescência e a consequência, de forma a identificar a conformidade dos agentes com as normas e regras existentes no ambiente institucional. No pilar cognitivo, os fatores são a coerência e a convergência. É importante explicitar a diferença entre aquiescência e convergência, de forma a delimitar as fronteiras dos pilares normativo e cognitivo: enquanto a primeira diz respeito ao consentimento quanto ao aparato normativo institucional, a segunda se refere ao compartilhamento de interesses sem que este dependa de um ambiente institucional formalizado para consolidar-se. 
Procurando aferir a capacidade do Polo de Defesa de Santa Maria (RS) para fomentar inovações a partir de esforços de interação entre Estado (Prefeitura e Forças Armadas), universidades (federal e privadas) e empresas, Florio (2018) aplicou questionário semi-estruturado aos atores participantes do referido Polo. Entre as inquirições estava a avaliação das categorias autonomia, autoridade, aquiescência, consequência, coerência e convergência como variáveis linguísticas moduladas com adjetivos de intensidade - alta, média ou baixa -. As respostas foram agrupadas por frequência.

Os resultados apontam clivagens entre os pilares intitucionais do Polo. A maioria dos respondentes entendeu haver alta autononomia, autoridade e aquiescência. No entanto, a consequência obteve frequência elevada e idêntica entre si nos estratos alta e média, e predominou a percepão de baixa convergência entre os atores. A partir desta aferição, a pouca efetividade do Polo em fomentar processos locais de inovação tem uma hipótese consistente relacionada às fragilidades do arranjo institucional, especialemente no plano cultural-cognitivo.

\section{Considerações Finais}

O presente esforço buscou demonstrar a relação existente entre os a inovação tecnológica e o papel das instituições envolvidas no desenvolvimento destas, argumentando que as interações entre atores também podem ser responsáveis pela produção de inovações tecnológicas. Para tanto, foram retomadas as abordagens teóricas da tríplice hélice e dos sistemas de inovação, de forma a elucidar os problemas destas e propor uma análise baseada nos componentes institucionais subjacentes ao ambiente interacional.

Na primeira seção, a abordagem quanto à tríplice hélice buscou elucidar o contexto de formação do conceito e problematizar sua aplicação indiscriminada. Reconhece-se a importância de complexificar a análise de acordo com o ambiente observado, incluindo mecanismos e variáveis oriundos de outras áreas do conhecimento. A crítica aqui realizada diz respeito à adoção da noção de tríplice hélice tendo subjacente um fím comum aos participantes, no qual a simples existência dos setores industrial, acadêmico e político é suficiente para o sucesso de processos de institucionalização e para a observação de colaborações frutíferas entre diferentes indivíduos e organizações. Ademais, a abordagem é pouco clara quanto a uma definição de instituições e a aplicação de sua ao processo de inovação pode ser capaz de integrar as diversas explicações

$\mathrm{Na}$ segunda seção, retomando-se a literatura sobre sistemas de inovação, foram apresentadas as diversidade de níveis analíticos organizados quanto à localização do sistema de inovação, seja este em âmbito regional, nacional ou setorial, ou por ancoragem do processo de inovação por produto, por tecnologia ou por um conjunto de produtos e processos complementares entre si. Cada um destes níveis de análise carrega elementos importantes quando da coordenação do processo de institucionalização, mas, que analisados individualmente, não produzem uma explicação completa quanto à organização de sistemas de inovação. Na medida em que os planos analíticos da inovação inserem-se em planos políticos e econômicos mais amplos, há dificuldade de articular os processos internos aos recortes sistêmicos e o seu entorno.

Na última seção, foram apresentados os três pilares de Richard Scott: regulativo, normativo e cognitivo, buscando explicitar variáveis que permitam a mensuração e observação empírica destes. São elas: autoridade, aquiescência, consequência, coerência e convergência. Estas variáveis objetivam uma definição abrangente quanto ao processo de institucionalização e a classificação de instituições, de forma a viabilizar observações 
práticas sobre o papel de aspectos imateriais na construção de relacionamentos que habilitem a produção de inovações tecnológicas a partir de perspectivas multidisciplinares. Uma primeira operacionização em um plano regional é introduzida. Como resultado obteve-se uma hipótese qualificada para a falta de resultado inovativo de uma arranjo institucional construído especificamente e como operação de três anos consecutivos. O modelo dialoga com as proposições de Scott (2013), pode ser aprimorado com uso complementar de outros instrumentos.

É necessário também ressaltar que os arranjos institucionais observados em vigência atualmente são um subconjunto do amplo espectro de possibilidades institucionais potenciais. Um modelo de sucesso adotado por determinado país ou recomendado por determinada organização não constitui uma alternativa única e excludente às demais na construção de uma economia de mercado capaz de funcionar à contento. A análise institucional deve ser capaz de lidar com as particularidades locais, de forma a perceber quais os fatores imateriais apresentam preponderância na construção, manutenção e transformação das estruturas institucionais. A partir deste estudo, o conhecimento quanto às práticas existentes abre caminho para a produção de explicações quanto à transformação institucional.

\section{Referências Bibliográficas}

ARRIGHI, G. A Ilusão do Desenvolvimento. Petrópolis, RJ: Vozes, 1997.

ARRIGHI, G.; SILVER, B. J.; BREWER, B. D. Industrial Convergence, Globalization, and the Persistence of the North-South Divide. Studies in Comparative International Development, v. 38, n. 1, p. 3-31, 2003.

ARTHUR, W. B.. Increasing Returns and Path Dependence in the Economy. Ann Arbor; University Michigan Press, 1994.

BENNER, M.; SANDSTRÖM, U. Institutionalizing the triple helix: Research funding and norms in the academic system. Research Policy, v. 29, n. 2, p. 291$301,2000$.

BRESCHI, S.; MALERBA, F. Sectoral Innovation Systems: Technological Regimes, Schumpeterian Dynamics, and Spatial Boundaries. In: Systems of innovation:

Technologies, institutions and organizations. Abingdon, Oxon: Routledge, 2005. p. $130-156$.

CARLSSON, B. et al. Innovation systems: analytical and methodological issues. Research Policy, v. 31, n. 2, p. 233-245, 2002.

CASSIOLATO, J. E.; LASTRES, H. M. M. Sistemas de Inovação e Desenvolvimento: as implicações de política. São Paulo em Perspectiva, v. 19, n. 1, p. 34-45, 2005.

CASSIOLATO, J. E.; MATOS, M. P. DE; LASTRES, H. M. M. Innovation Systems and Development. In: CURRIE-ALDER, B. et al. (Eds.). . International Development: Ideas, Experiments and Prospects. [s.1.] Oxford Scholarship Online, 2014. p. 45-66.

DAGNINO, R. A Relação Universidade-Empresa no Brasil e o "Argumento da Hélice Tripla”. Convergência, n. 35, p. 253-291, 2004. 
DAVID, P.. Clio and the economics of QWERTY. American Economic Review, 75, p. 332-337, 1985.

DZISAH, J.; ETZKOWITZ, H. Triple Helix Circulation: The Heart of Innovation and Development. International Journal of Technology Management and Sustainable Development, v. 7, n. 2, p. 101-115, 2008.

ELVEKROK, I. et al. Firm innovation benefits from regional triple-helix networks. Regional Studies, p. 1-11, 2017.

ETZKOWITZ, H.; DE MELLO, J. M. C.; ALMEIDA, M. Towards “meta-innovation" in Brazil: The evolution of the incubator and the emergence of a triple helix. Research Policy, v. 34, n. 4, p. 411-424, 2005.

FLORIO, Bibiana Poche. Arranjos Institucionais para Inovação Tecnológica do Polo de Defesa e Segurança de Santa Maria. Dissertação de Mestrado. Programa de PósGraduação em Economia e Desenvolvimento. Universidade Federal de Santa Maria, 2018

HODGSON, G. What are institutions? Journal of Economic Issues, 1, 2006.

JEROME, L. W. Triple Helix Knowledge Clusters: Accelerating Innovation and Creating Transformative Networks. In: SAAD, M.; ZAWDIE, G. (Eds.). Theory and Practice of Triple Helix Model in Developing Countries: Issues and Challenges. New York, NY: Routledge, 2011. p. 9-24.

JOHNSON, B.; LUNDVALL, B.-A. Sistemas nacionales de innovación y aprendizaje institucional. Revista de Comercio Exterior, p. 695-704, 1994.

LEYDESDORFF, L. Synergy in Knowledge-Based Innovation Systems at National and Regional Levels: The Triple Helix Model and the Fourth Industrial Revolution. Journal of Open Innovation: Technology, Market, and Complexity, v. 4, n. 2, p. 1-13, 2018.

LEYDESDORFF, L; ETZKOWITZ, H. Emergence of a Triple Helix of universityindustry-government relations. Science and Public Policy, v. 23, n. 5, p. 279-286, 1996.

LUNDVALL, Bengt-Åke. Innovation System Research: Where it came from an where it might go. In: FIFTH GLOBELICS CONFERENCE 2007, Saratov. Anais... Saratov

MOWERY, D. C. National security and national innovation systems. Journal of Technology Transfer, v. 34, n. December 2008, p. 455-473, 2009.

PALTHE, J. Regulative, Normative, and Cognitive Elements of Organizations: Implications for Managing Change. Management and Organizational Studies, v. $1, \mathrm{n}$. 2, p. 59-66, 2014.

RENNSTICH, J. K. The Making of a Digital World: The Evolution of Technological Change and How It Shaped Our World. New York, NY: Palgrave Macmillan, 2008.

RODRIK, D. One Economics, Many Recipes: Globalization, Institutions and Economic Growth. Princeton, NJ: Princeton University Press, 2007. v. 1

RUTHERFORD, M.. Institutions in economics: the old and the new institutionalism. 
Cambridge University Press, 1984.

SCHUMPETER, J. A. Teoria Do Desenvolvimento Econômico: Uma Investigação Sobre Lucros, Capital, Crédito, Juro E O Ciclo Econômico. São Paulo, SP: Editora Nova Cultural Ltda., 1997.

SCOTT, W. R. Institutions and Organizations: ideas, interests and identities. Thousand Oaks, CA: Sage Publications, 2008.

SCOTT, W. R Institutions and Organizations: ideas, interests and identities. Thousand Oaks, CA: Sage Publications, 2013.

SOETE, L.; VERSPAGEN, B.; WEEL, B. TER. Systems of innovation. Handbook of the Economics of Innovation, v. 2, n. 1, p. 1159-1180, 2010.

THELEN, K. How Institutions Evolve. In: MAHONEY, J.; RUESCHEMEYER, D. (Eds.). . Comparative Historical Analysis in the Social Sciences. New York, NY: Cambridge University Press, 2003. p. 208-240. 